\title{
Rapid climate driven shifts in wintering distributions of three common waterbird species
}

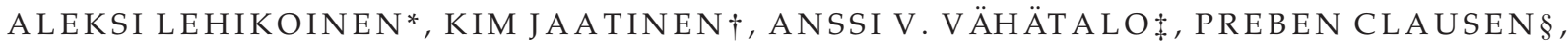
OLIVIA CROWEף, BERNARD DECEUNINCK\|, RICHARD HEARN**, CHAS A. HOLT††,

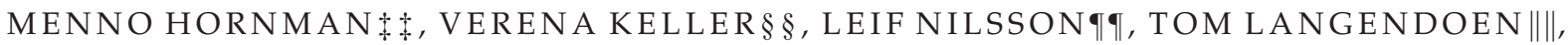
IRENA TOMÁNKOVÁ***, JOHANNES WAHL $+\dagger \dagger$ and ANTHONY D. FOX§

*Finnish Museum of Natural History, University of Helsinki, P.O. Box 17, Helsinki FI-00014, Finland, †Evolution, Ecology E Genetics, Research School of Biology, ANU College of Medicine, Biology E Environment, The Australian National University, Canberra, ACT 0200, Australia, †ARONIA Coastal Zone Research Team, Abo Akademi University and Novia University of Applied Sciences, Raseborgsvägen 9, Ekenäs FI-10600, Finland, §Department of Bioscience, Aarhus University, Kalø, Grenåvej 14, Rønde DK-8410, Denmark, 『BirdWatch Ireland, Unit 20 Block D Bullford Business Campus, Kilcoole, County Wicklow Ireland, ||LPO-BirdLife France, Fonderies Royales, 8 rue du Dr Pujos, Rochefort Cedex BP 90263 F-17305, France, **Wildfowl E Wetlands Trust (WWT), Slimbridge, Glos GL2 7BT, UK, ††British Trust for Ornithology, The Nunnery, Thetford, Norfolk IP24 2PU, UK, +\$Sovon Dutch Centre for Field Ornithology, P.O. Box 6521, Nijmegen 6503 GA, The Netherlands, §§Swiss Ornithological Institute, Sempach CH-6204, Switzerland, $\uparrow \uparrow$ Department of Biology, University of Lund, Ecology Building, Lund S-223 62, Sweden, ||||Wetlands International, Horapark 9, Ede 6717 LZ, The Netherlands, ***Quercus, School of Biological Sciences, Queen's University Belfast, MBC, 97 Lisburn Road, Belfast, Northern Ireland BT9 7BL, UK †† †Dachverband Deutscher Avifaunisten e.V. (DDA), Federation of German Avifaunists, An den Speichern 6, Münster D-48157, Germany
\end{abstract}

\begin{abstract}
Climate change is predicted to cause changes in species distributions and several studies report margin range shifts in some species. However, the reported changes rarely concern a species' entire distribution and are not always linked to climate change. Here, we demonstrate strong north-eastwards shifts in the centres of gravity of the entire wintering range of three common waterbird species along the North-West Europe flyway during the past three decades. These shifts correlate with an increase of $3.8{ }^{\circ} \mathrm{C}$ in early winter temperature in the north-eastern part of the wintering areas, where bird abundance increased exponentially, corresponding with decreases in abundance at the south-western margin of the wintering ranges. This confirms the need to re-evaluate conservation site safeguard networks and associated biodiversity monitoring along the flyway, as new important wintering areas are established further north and east, and highlights the general urgency of conservation planning in a changing world. Range shifts in wintering waterbirds may also affect hunting pressure, which may alter bag sizes and lead to population-level consequences.
\end{abstract}

Keywords: global warming, goldeneye, goosander, ice cover, population distribution, tufted duck

Received 7 March 2013; revised version received 7 March 2013 and accepted 13 March 2013

\section{Introduction}

Several studies have shown range margin shifts in over 20 different taxonomic groups in recent years (Parmesan, 2006; Maclean et al., 2008; Brommer \& Møller, 2010; Chen et al., 2011). To date, such studies have mainly focused on documenting changes at the edges of species' distributions, and studies concerning shifts throughout entire ranges are rare. The expansion of the northern boundary of European butterflies towards north has been much

Present address: Anssi V. Vähätalo, Department of Biological and Environmental Science, University of Jyväskylä, P.O. Box 35, Survontie 9, Jyväskylä FI-40014, Finland

Correspondence: Aleksi Lehikoinen, tel./fax +358 45 1375732, e-mail: aleksi.lehikoinen@helsinki.fi stronger than retraction of the southern boundary (Parmesan et al., 1999). Maclean et al. (2008) showed that the centre of gravity of wintering distributions of five Northern European wader populations have shifted $95 \mathrm{~km}$ northeastwards. Abundance of several European breeding bird species increased along a northern range margin and concomitantly decreased at the southern range margin (Jiguet et al., 2010). La Sorte \& Thompson (2007) showed that the northern boundary and centre of wintering bird abundance had shifted northwards, but they did not investigate the southern edge of these distributions, which would be crucial for the determination of spatial shifts of entire ranges.

Although it has been argued that range shifts are caused by climate change, direct links have rarely been demonstrated, and annual variations in the distribution 
of populations have hitherto not been convincingly linked to climatic fluctuations (Brommer \& Møller, 2010). The only regional examples of climatic effects on population ranges, of which we are aware, are those showing that fewer wintering waders occurred in southwestern United Kingdom during warmer winters (Austin \& Rehfisch, 2005) and that the wintering distribution of black brant (Branta bernicla nigricans) in Alaska shifted northwards as a response to climatic oscillation (Ward et al., 2009). However, such annual distribution shifts have not been demonstrated for entire populations at the migration flyway level. The lack of studies demonstrating effects across entire distribution ranges is likely to be because estimating population sizes and trends of most widespread species, over such vast geographical areas, is extremely challenging. This task, however, represents a challenge that researchers must confront, if we wish to conserve populations under changing conditions.

Wintering waterbirds are highly likely to show distributional shifts due to climate change, as they respond rapidly to weather conditions (Ridgill \& Fox, 1990; Lehikoinen et al., 2006; Rainio et al., 2006). Other environmental changes (e.g., eutrophication or wetland habitat creation) may affect the abundance of birds regionally rather than across entire flyways (Ma et al., 2010). For instance, breeding waterbird populations specifically occupying wetlands subject to excessive eutrophication have recently shown a dramatic decline in breeding numbers in Finland, which cannot be explained by other factors, such as hunting (Pöysä et al., 2013; see also Rönkä et al., 2005).

Waterbirds breeding in Northern Europe and Siberia have increasingly delayed their southward autumn migration, and this delay is thought to be linked to climate warming (Lehikoinen \& Jaatinen, 2012). Furthermore, spring arrival dates of waterbirds in the same flyway were linked with climatic oscillation (Vähätalo et al., 2004; Rainio et al., 2006), and, for instance, the spring arrival of common eiders to their North European breeding areas has advanced during recent decades (Lehikoinen et al., 2006). Such changes, coupled with indications of past range shifts (Nilsson, 2008; Skov et al., 2011), corroborate the notion that waterbirds are highly responsive to changes in climate (Rainio et al., 2006). Based on this background information, we hypothesize that climate change does cause shifts in the centre of the gravity of the whole flyway population. From this hypothesis, we draw two predictions relating to waterbirds in the northern hemisphere: (i) that numbers will increase in the northern parts of flyways, coupled with a decrease in the southern parts and (ii) as waterbird numbers respond to temperature, we predict that in mild winters waterbird numbers will be higher in countries at the northern edge of the flyway and lower on the southern edge, and vice versa. To test these predictions, we examine a long-term (31 years, 19802010) dataset on the wintering distributions of three common European waterbird species: the goosander (Mergus merganser), the common goldeneye (Bucephala clangula; hereafter goldeneye) and the tufted duck (Aythya fuligula). We aim to elucidate potential range shifts, their magnitude and their links to temperature fluctuations across the North-West European flyway.

\section{Materials and methods}

\section{Duck data}

We utilized three decades (1980-2010) of site-based count data to determine the wintering distributions of three common waterbird species. In this study, we track changes in species abundance in nine countries (Finland, Sweden, Denmark, Germany, the Netherlands, Switzerland, Great Britain, the island of Ireland and France) covering a climatic gradient throughout the $3000 \mathrm{~km}$ long southwest-northeast flyway of the study species (Perdeck \& Clason, 1980; Scott \& Rose, 1996). The data originate from the International Waterbird Census (IWC, coordinated by Wetlands International; Delany, 2005) and the Finnish winter bird count scheme (Hildén et al., 1991) conducted primarily in January in nine countries during 1980-2010 (for details of the national count schemes and data, see Table 1). In general, the count data were compiled separately for each country, with the exception of Sweden, which was split into two areas, because the northern and southern parts of this large country differ considerably in terms of winter climate (Nilsson, 2008). In addition, the Republic of Ireland and Northern Ireland have been combined, since they are geographically separate from Great Britain.

Our study species are the three common and widely distributed diving duck species in Europe, which exploit both marine and freshwater habitats. The North-West European flyway, to which these species belong, is the best documented of all flyways, with the longest running monitoring schemes. These three study species and the long-tailed duck are the most abundant wintering diving ducks in the northern edge of the flyway near the edge of the ice cover. However, we excluded the long-tailed duck and other sea ducks from the analyses, because these species are wintering off-shore and majority of the population is not surveyed annually (Skov et al., 2011). These three remaining study species are exceptionally suited for studying the impact of climate change, not only because they are common and exhibit relatively stable population sizes (Wetlands International, 2012), but also because they are truly dependent on open water as they feed on fish and/or benthic organisms (Cramp \& Simmons, 1977). Because of this diet, diving ducks may await the onset of winter, and only migrate southward when bodies of water start to freeze over. Dabbling ducks, which feed in shallow water that freezes over rapidly at sub-zero temperatures, also avoid the zero-degree isotherm and do so by rapid and long-distance movements before the 
onset of winter (Ridgill \& Fox, 1990; Dalby et al., 2013). In addition to this, the population sizes of several species of swans and geese have increased markedly during the recent decades (Wetlands International, 2012), which may complicate the investigation of the potential effects of climate change on range shifts. The combined population size of the study species in this flyway is estimated to be more than 2.6 million individuals (Wetlands International, 2012) and the estimated annual hunting bag size of the three species throughout Europe is more than 400000 individuals (Hirschfeld \& Heyd, 2005).

\section{Climate data}

We used the average temperature measured in southern Finland by the Finnish Meteorological Institute during a 2-month period prior to the censuses (16 November-15 January), as a proxy for early winter temperature at the northeastern edge of the flyway. Data from approximately 100 Finnish weather stations were interpolated to a $10 \times 10 \mathrm{~km}$ grid of virtual weather stations (Venäläinen et al., 2005). From these, we calculated the mean early winter temperature in southern Finland $\left(60-64^{\circ} \mathrm{N} ; 20-31^{\circ} \mathrm{E}\right.$, Supplementary Figure S1a). The winter temperature in southern Finland correlated with the winter temperature over large spatial areas in northern Europe (Supplementary Figure S1a). In the northeastern part of the flyway, the early winter temperature increased by $3.8^{\circ} \mathrm{C}$ during the study period (Supplementary Figure S1b), which indicates the strong potential for climate driven changes wintering distributions of waterbirds.

\section{Statistical analyses}

Data were analyzed by using site-specific duck abundance from each country. The response variables in our analyses, that is, population trends and annual abundances of goosander, goldeneye and tufted duck, were estimated using the Trends and Indices for Monitoring data (TRIM) software (Pannekoek \& van Strien, 2004). This software is commonly used by many European bird monitoring schemes. TRIM uses a generalized estimating equation algorithm to estimate a population index from count data taking into account overdispersion and serial correlation in the data. It also interpolates missing observations (sites with lacking censuses in some years) using a Poisson general log-linear model (Pannekoek \& van Strien, 2004; the software and the manual are freely available on www.ebcc.info).

Because the duck counts were not always repeated at each count-site annually over the study period, we estimated the change in bird abundance in each country by generating annual population indices and using the latest national wintering population estimates (see Table 2 for details). We did this by anchoring the species and country-specific wintering number estimate at a particular year in the time series with the abundance indices produced by the TRIM-software. Thus, if a population of a species in a given country was estimated to be 50000 birds in year $t$, when the annual abundance index had a value of 1 , index values of 1.5 and 2.5 in year $t+n$, where $n$ is the number of years passed, would mean that the population has increased by 25000 and 75000 individuals, 
Table 2 Region wide estimates of wintering tufted ducks, goldeneyes and goosanders including the survey year and the reference of the report, where the results have been published. Values in brackets are not used in the analyses, as they do not concern the birds from the study flyway

\begin{tabular}{llcccl}
\hline Area & Survey year & Tufted duck & Goldeneye & Goosander & Reference \\
\hline Finland & $1990-1992$ & 1000 & 1000 & 6000 & Koskimies (1993) \\
Sweden N & 2004 & 173838 & 45986 & 15341 & Nilsson (2008) \\
Sweden S & 2004 & 51111 & 25886 & 2662 & Nilsson (2008) \\
Denmark & 2008 & 162247 & 64977 & 13846 & Petersen et al. (2010) \\
Germany & $2000-2005$ & 325000 & 65000 & $33500^{*}$ & DDA unpublished \\
Netherlands & $2006-2010$ & 220000 & 12000 & 11000 & Hornman et al. (2013) \\
Switzerland & $1982,1997,2010 \dagger$ & 211631 & 14513 & {$[5743]$} & Keller (2011) \\
G. Britain & $2005-2009$ & 110000 & 9600 & {$[12$ 000] } & Musgrove et al. (2011) \\
Ireland & $2000-2004$ & 36610 & 2175 & {$[0]$} & Crowe et al. (2008) \\
France & $2007-2011$ & 41383 & & Deceuninck et al. (2012) \\
\hline
\end{tabular}

*Northern Germany only.

$\dagger$ Tufted duck 1982, Goldeneye 1997, and Goosander 2010.

respectively. To estimate the change in bird numbers over the study period, we calculated the difference between the averages of the first three, and last 3 years in the time series (see Table 2 for details on national population estimates). We used an average of 3 years to balance out the effects of potential single extreme years. We must stress that these abundance estimates are coarse, but we use them here to represent the magnitude of the change in real numbers of individuals.

We built two different linear autoregressive models to test how the log-transformed annual species and country-wide bird abundances are associated with variation in the annual temperature at the northeastern edge of the flyway and bird abundances in the same country year before. The equation adopted in the first approach was:

$$
\log \left(N_{t+1}\right) \approx \log \left(N_{t}\right)+W_{t+1}
$$

where $N$ is the population abundance in year $t+1$ and $t$, and $W$ is the early winter temperature in South Finland in year $t+1$. This model takes into account, and corrects for, temporal autocorrelation when estimating the direct effect of winter temperature on the number of wintering birds (higher temperature increases bird numbers and lower temperature decreases bird numbers). The second model took the form:

$$
\log \left(N_{t+1}\right) \approx \log \left(N_{t}\right)+\Delta W_{t, t+1}
$$

which was otherwise similar, except that the effect of weather was modelled on the difference in temperature between two subsequent years. Thus, we expect that wintering numbers would increase in the case where temperature has been higher in year $t+1$ than in year $t$, and vice versa. We compared these two models using AICc (Burnham \& Anderson, 2002).

\section{Results}

Over the past three decades, the numbers of all three wintering ducks increased at the northeastern edge of the flyway with a simultaneous decrease in the southwestern edge of their respective distributions (Figs 1 and 2). This change was particularly pronounced
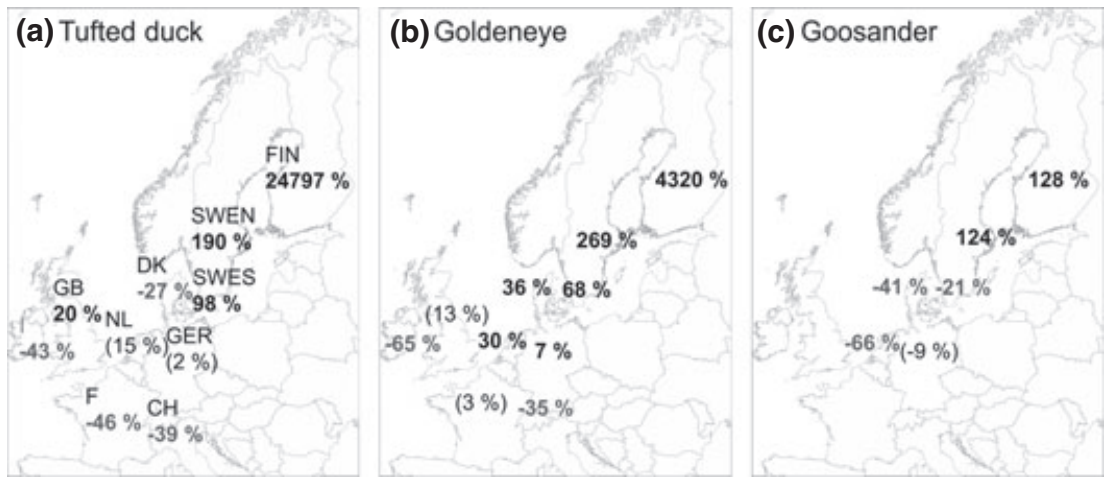

Fig. 1 Winter percentage change in abundance of (a) tufted duck, (b) goldeneye and (c) goosander in nine north and west European countries in 1980-2010 (slightly shorter periods in some countries; Supplementary Table 1). Significant population changes are bolded in black (increase) and dark grey (decrease), values in brackes represents no significant change. Relatively few north European goosanders winter as far south and west as France, Great Britain and Ireland (Scott \& Rose, 1996), and Swiss birds partly belong to the Central/West European flyway population, so the Netherlands was defined as the south-western edge of the flyway for this population. Estimated population changes in numbers of individuals are shown in Table 4. 
during the last 15-20 years based on annual fluctuations in the abundance indices (Figs 1 and 2).

In Finland, the number of tufted duck, goldeneye and goosander increased by $24800 \%, 4320 \%$ and $128 \%$, respectively, or by 38000 birds (Figs 1 and 2; Tables 3 and 4). In northern Sweden, the numbers of birds increased by over 80000 for all three species with $190 \%, 269 \%$ and $124 \%$ increases for tufted duck, goldeneye and goosander, respectively (Figs 1 and 2; Tables 3 and 4).

At the southwestern edge of the flyway, tufted ducks decreased by $46 \%$ in France, $43 \%$ in Ireland and 39\% in Switzerland or altogether by 104000 birds. Goldeneyes decreased significantly in Ireland and in Switzerland by $63 \%$ and $35 \%$, respectively, representing together a loss of 12000 birds. Recent short-term declines of goldeneyes (since the mid-1990s) occurred in other southwestern areas; the Netherlands, Great Britain and France (Figs 1 and 2; Tables 3 and 4). At the southwestern edge of the flyway, the numbers of goosander decreased by $66 \%, 41 \%$ and $21 \%$ in the Netherlands, Denmark and southern Sweden, respectively, or together by 51000 birds (Figs 1 and 2; Table 4). In the south-central part of the flyway, Switzerland, the number of tufted ducks and goldeneyes decreased by 70000 birds (Fig. 2; Table 4). Despite these rapid changes in national abundances, the combined population size estimate of all three species has remained relatively stable during 1987-2009, when data from all nine study countries were available (Fig. 3 ).

In half of the country-specific analyses, the annual winter abundances were significantly positively dependent on the population abundance in the year before and thus positively autocorrelated (Tables 5 and 6). This was especially the case at both edges of the flyway: Finland, Sweden in the north and in Netherlands (goosander), Switzerland, United Kingdom (goldeneye), Ireland and France in the south (Tables 5 and 6). The annual fluctuations in duck abundances were more strongly linked to the direct effect of changes in early winter temperatures at the northeastern edge of the flyway (Finland and Sweden), as in six cases the direct effect models were better $(\triangle \mathrm{AICc}>2)$ than models

Fig. 2 National trends in winter abundance of tufted duck (a-j), goldeneye $(\mathrm{k}-\mathrm{t})$ and goosander $(\mathrm{u}-\mathrm{z})$ in Finland, Northern and Southern Sweden, Denmark, Germany, the Netherlands, Switzerland, Great Britain, Ireland and France in 1980-2010 represented as estimated population sizes in each country. The unit of the $y$-axis is thousands of birds, and it has been calculated using annual population indices of trends and indices for monitoring data analysis and national countrywide wintering estimates (see methods and Tables 2 and 4).
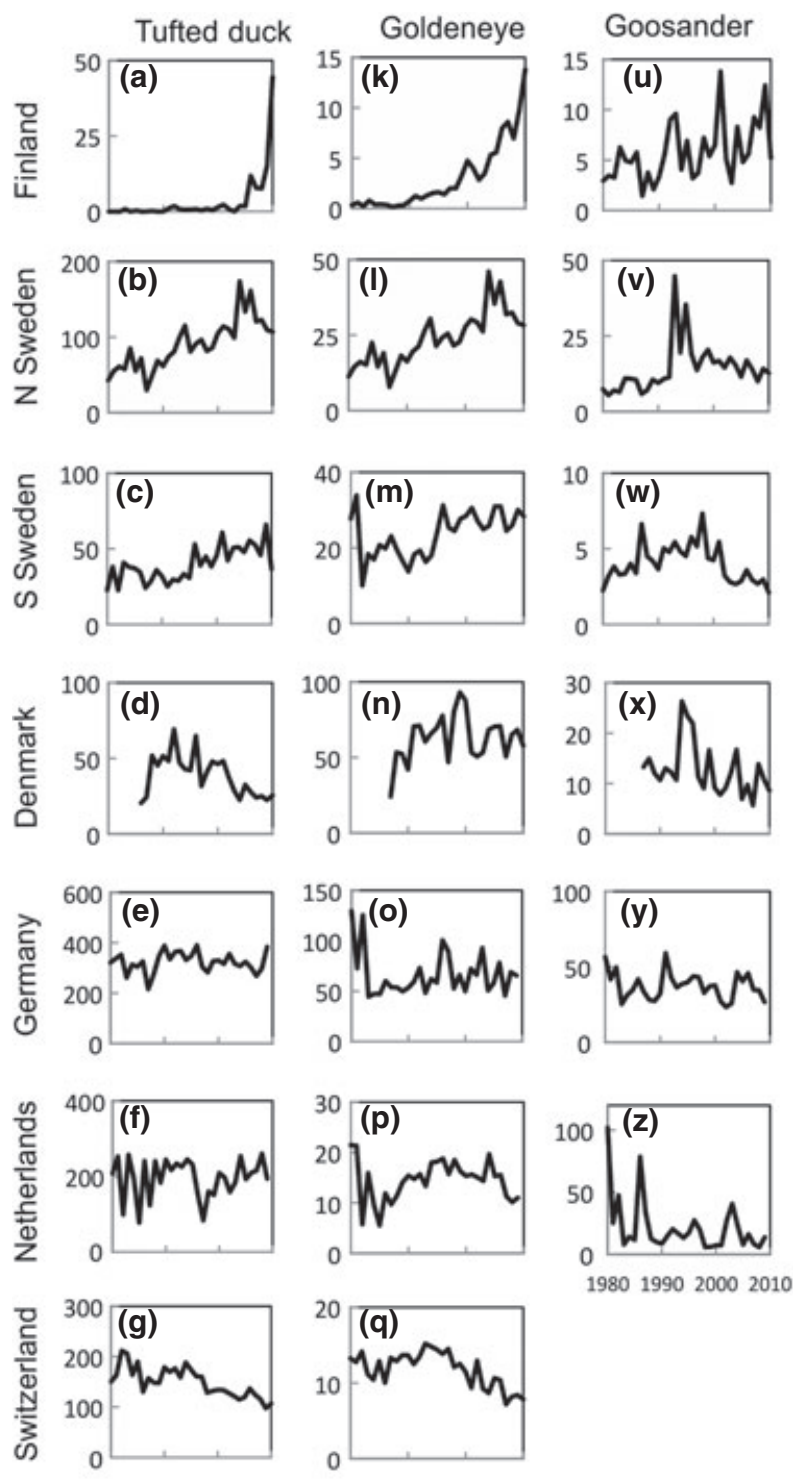

1980199020002010
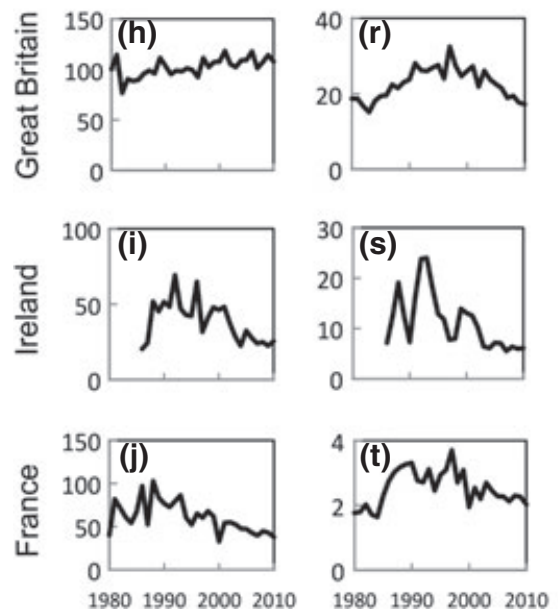
Table 3 Annual growth rates of wintering populations of tufted ducks, goldeneyes and goosanders based on Trends and Indices for Monitoring data-analyses of annual mid-winter count data from wetlands in all countries. Growth rate value 0.195 means that population increased 19.5\%/year. Mean annual growth rate and total change in abundance during the study period in each study area are shown; significant growth rates in bold. ' - ' indicates areas outside of the flyway of the species, which were not used in the analyses

\begin{tabular}{|c|c|c|c|c|c|c|c|}
\hline \multirow[b]{2}{*}{ Area } & \multirow[b]{2}{*}{ Study period } & \multicolumn{2}{|l|}{ Tufted duck } & \multicolumn{2}{|l|}{ Goldeneye } & \multicolumn{2}{|l|}{ Goosander } \\
\hline & & Growth rate & Change (\%) & Growth rate & Change (\%) & Growth rate & Change (\%) \\
\hline Finland & 1980-2010 & $0.195 \pm 0.028$ & 24797 & $0.130 \pm 0.005$ & 4320 & $0.027 \pm 0.003$ & 128 \\
\hline Sweden N & 1980-2010 & $0.035 \pm 0.004$ & 190 & $0.043 \pm 0.003$ & 269 & $0.026 \pm 0.003$ & 124 \\
\hline Sweden S & 1980-2010 & $0.022 \pm 0.003$ & 98 & $0.017 \pm 0.002$ & 68 & $-0.008 \pm 0.003$ & -21 \\
\hline Denmark & 1987-2010 & $-0.013 \pm 0.006$ & -27 & $0.013 \pm 0.005$ & 36 & $-0.022 \pm 0.007$ & -41 \\
\hline Germany & 1980-2009 & $0.001 \pm 0.001$ & 2 & $0.002 \pm 0.001$ & 7 & $-0.003 \pm 0.002$ & -9 \\
\hline Netherlands & 1980-2009 & $0.005 \pm 0.003$ & 15 & $0.006 \pm 0.003$ & 21 & $-0.035 \pm 0.003$ & -66 \\
\hline Switzerland & 1980-2010 & $-0.017 \pm 0.001$ & -39 & $-0.015 \pm 0.002$ & -35 & - & - \\
\hline G. Britain & 1980-2010 & $0.006 \pm 0.001$ & 20 & $0.004 \pm 0.001$ & 13 & - & - \\
\hline Ireland & 1986-2010 & $-0.022 \pm 0.003$ & -43 & $-0.039 \pm 0.002$ & -63 & - & - \\
\hline France & 1980-2010 & $-0.021 \pm 0.001$ & -46 & $0.001 \pm 0.002$ & 3 & - & - \\
\hline
\end{tabular}

Table 4 Estimated change in absolute numbers of individuals in each study area between first three and last three study years. 'indicates that areas outside of the flyway of the species, not used in the analyses. Note that change in number of individuals and percentiles of growth rate (Table 3) does not necessarily match perfectly, as the trend of the percentiles is counted using all years during the study period but the change in individuals relates directly to the difference between the average of last three and first three study years

\begin{tabular}{lllrrr}
\hline Area & First 3 years & Last 3 years & Tufted duck & Goldeneye & Goosander \\
\hline Finland & $1980-1982$ & $2008-2010$ & 22400 & 9800 & 5400 \\
Sweden N & $1980-1982$ & $2008-2010$ & 60000 & 4500 & 5700 \\
Sweden S & $1980-1982$ & $2008-2010$ & 21700 & 20400 & -500 \\
Denmark & $1987-1989$ & $2008-2010$ & -25200 & -18300 & -18700 \\
Germany* & $1980-1982$ & $2007-2009$ & 40600 & -5600 & -48500 \\
Netherlands & $1980-1982$ & $2007-2009$ & -68400 & -5300 & - \\
Switzerland* & $1980-1982$ & $2008-2010$ & 12700 & -6700 & - \\
G. Britain & $1980-1982$ & $2008-2010$ & -7900 & 300 & - \\
Ireland & $1986-1988$ & $2008-2010$ & -27600 & \\
France* & $1980-1982$ & $2008-2010$ & & \\
\hline
\end{tabular}

*Germany, Switzerland and France share two larger wetlands, where birds could be partly included in estimates from both countries. However, in the trend analyses, the data from these sites have been split between countries.
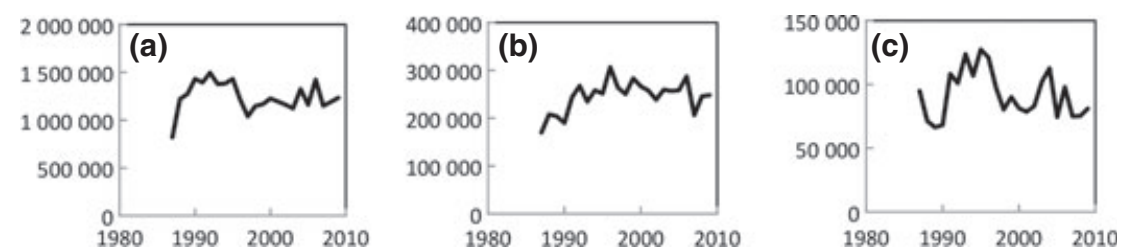

Fig. 3 Combined population estimates of (a) tufted ducks, (b) goldeneye and (c) goosander, during 1987-2009 when data were available from all nine study countries.

where the temperature difference between two subsequent years was used as an explanatory variable, whereas the opposite pattern was found only once (Fig. 4; Tables 5 and 6, Supplementary Table S1). In Finland, the annual change in abundance of tufted duck, goldeneye and goosander increased with increas- ing early winter temperatures, and the same was the case with tufted ducks in south Sweden (Fig. 4; Table 5). Compellingly, the southwestern parts of the flyway exhibited the opposite patterns: annual change in French goldeneye numbers and Dutch goosander numbers were significantly negatively associated with 


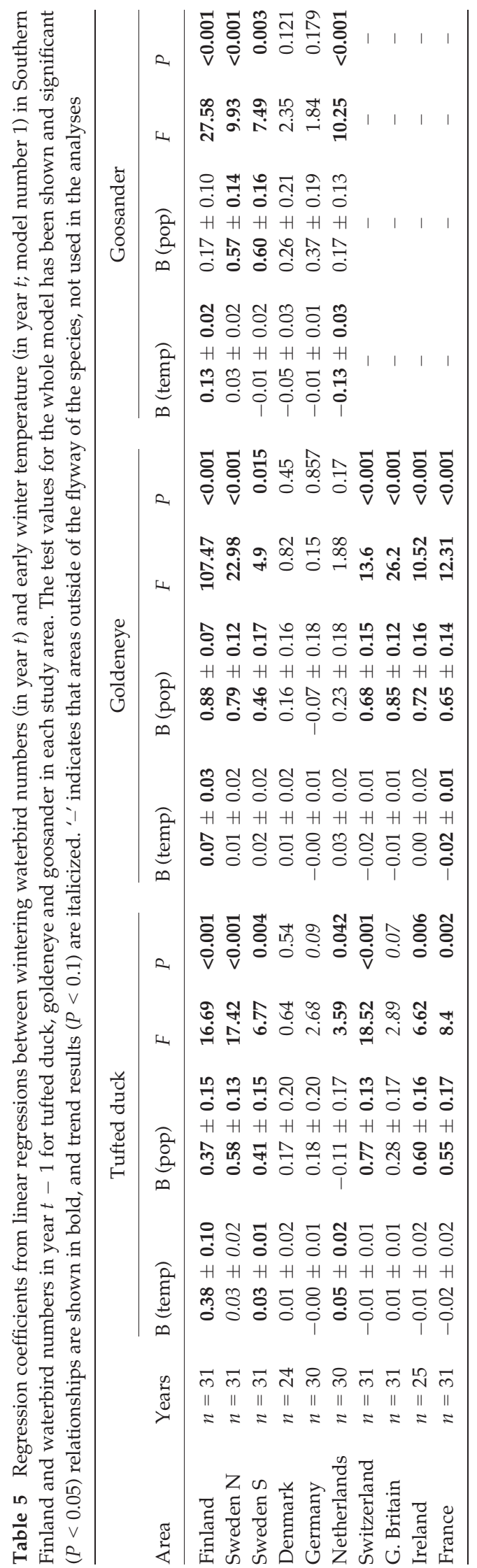

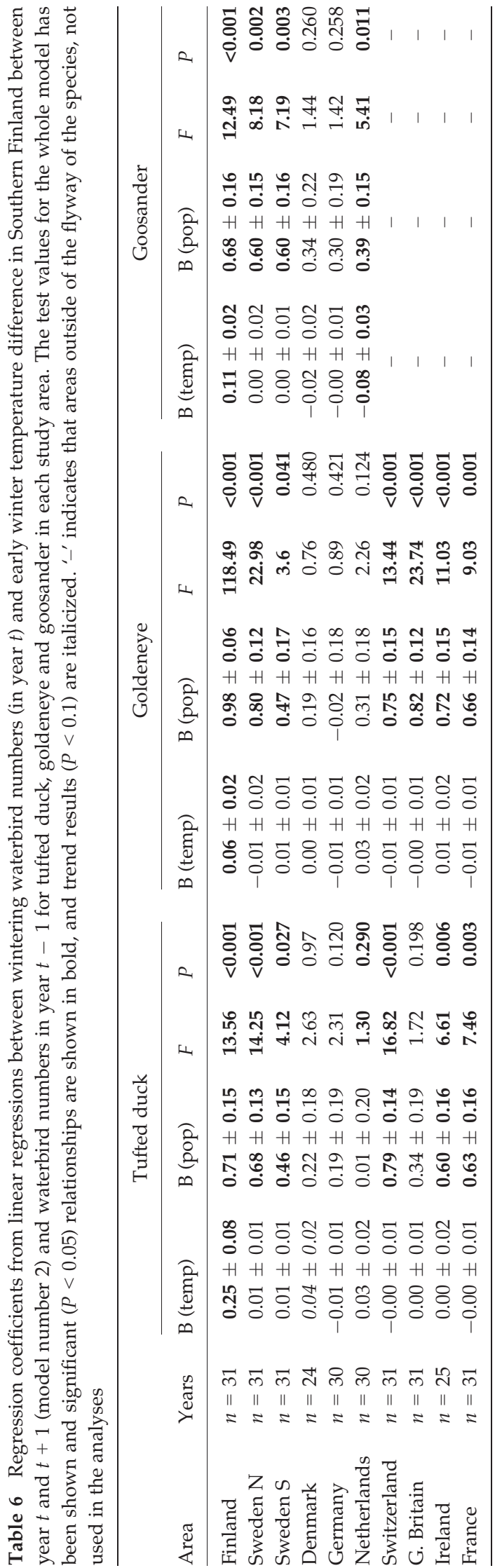




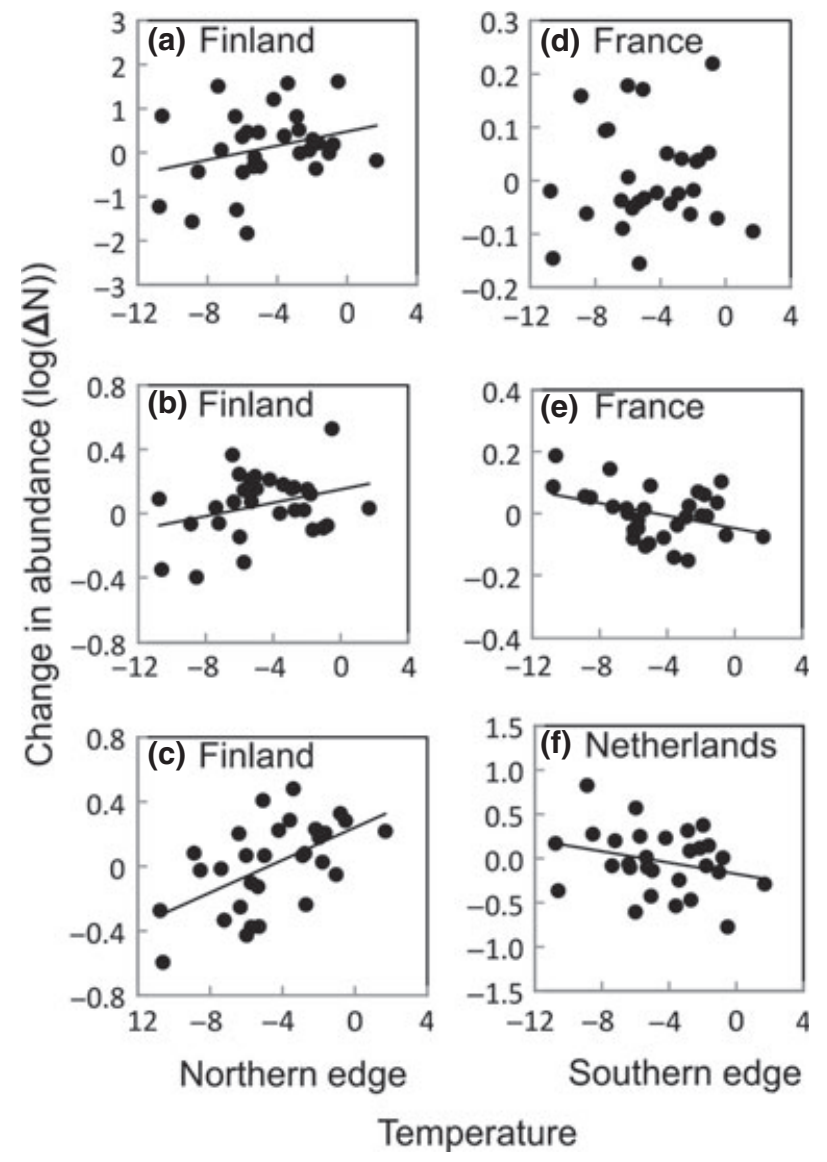

Fig. 4 Annual change in national winter population abundances of tufted duck $(a, d)$, goldeneye $(b, e)$ and goosander (c, f) on the northeastern edge (i.e., Finland, $\mathrm{a}-\mathrm{c}$ ) and southwestern edge (i.e., France, the Netherlands, $\mathrm{d}-\mathrm{f}$, respectively) in relation to early winter temperature in Finland in year $t+1$ (Table 5). The scale of $y$-axis is log-transformed difference between $N_{t+1}$ and $N_{t}$. Solid lines represent significant correlation.

the direct effect of early winter temperature at the northeastern edge of the flyway (Fig. 4; Table 5). The difference in temperature between two subsequent years was only significantly associated with wintering numbers of Dutch goosander (Tables 5 and 6; Supplementary Table S1). In the central part of the flyway, duck abundances were independent of temperature (Tables 5 and 6).

\section{Discussion}

Our results show, for the first time at the flyway level, that the wintering distributions of waterbird have shifted rapidly northeastward as a response to changes in temperature. The hypothesis for a climate driven shift in the wintering distribution of tufted ducks, goldeneyes and goosanders is supported by the fact that observations of increased duck numbers at the north- eastern edge of the flyway were corroborated by those of decreasing duck numbers at the southwestern edge of the flyway. Critically, annual fluctuations in bird numbers were directly linked with early winter temperature at both ends of the flyway, but especially on the northern edge of the distribution in all three species. Our findings also suggest that it is the direct effect of the temperature which drives the population changes and not the difference in temperatures between two subsequent years. Therefore, we believe that there are species-specific temperature thresholds, above which wintering abundance increases on the northern side of the distribution and thus increased temperature has a key role on large-scale changes in species distribution. Nevertheless, we cannot exclude the possibility that other environmental factors have acted together with global warming.

At the edges of the duck distributions, the wintering numbers in all three species were strongly positively linked with the wintering numbers the year before in the same region. This positive temporal autocorrelation in numbers suggests that large parts of the populations are likely to show wintering philopatry on a larger spatial scale (here manifested at the national level used in this analysis). Nevertheless, this does not exclude the possibility that birds can move within winter at smaller spatial scales, as documented, for example, amongst individually marked tufted ducks (Gourlay-Larour et al., 2012). In addition, several other waterbirds are known to show winter site fidelity to some extent (Guillemain et al., 2009; Petersen et al., 2012). This implies that some part of the population is responding to new feeding opportunities as these arise from changes in temperature, resulting in the observed shifts in range. To understand these mechanisms in more detail, we need to know which individuals are more likely to respond to temperature (e.g., are they males, adults, young, good or low-quality birds and of which previous wintering provenance?).

The wintering population sizes of the studied species in the two northernmost countries in this study (Finland and Sweden) have increased by more than 140000 individuals over the past three decades. This number of individuals represents over $5 \%$ of the populations of the three species in the North-West European flyway (Wetlands International, 2012). Correspondingly, countries in the southwestern parts of the flyway, the Netherlands, Switzerland, Ireland and France, have lost over 128000 birds over the same period. In this analysis, we have only analyzed count data from three diving duck species, which we consider the most likely to show such range shifts in response to temperature change and hence ice-free habitat up against the northeastern limit of their winter range. There are recent indications 
that the wintering populations of many waterbird species have increased in northern Europe (Baltic region; Nilsson, 2008; Skov et al., 2011) and decreased in southern and western areas (Crowe et al., 2008; Rendón et al., 2008; Keller, 2011). Therefore, we believe that climate driven shifts in the central gravity of species distribution could be a general pattern amongst many more European waterbird species than studied here, and should be examined in more detail.

Waterbird population shifts are of both political and socio-economic importance. Waterbirds are included in international and national legislations and widely harvested species (Wetlands International, 2006). Furthermore, waterbirds are highly dependent on wetlands, including many threatened habitat types throughout the world (Williams, 1993). Waterbird abundance is one of the most commonly used designation criteria to protect wetland sites (Wetlands International, 2006). There are several wetland and waterbird site safeguard programmes, including the Ramsar Convention, the African-Eurasian Waterbird Agreement and the European Union Special Protection Areas network under the European Union Directive on the Conservation of Wild Birds (Council Directive 2009/147/EC). These programmes represent the basis for conserving necessary habitats to safeguard populations of migratory waterbirds. As global warming is predicted to escalate in the near future, particularly so at higher latitudes (Intergovernmental Panel on Climate Change (IPCC), 2007), we can expect increasing numbers of waterbirds staging and wintering in northeastern areas, formerly inaccessible to them. These new staging and wintering areas may become of vital importance for waterbird populations and, may not be included in any of the environmental safeguard programmes. Conversely, we can expect to see birds increasingly retracting from sites further south and west within the wintering range, some of which were designated specifically to protect these populations (cf. Kujala et al., 2011). Because of this, local managers should consider climate change as a possible cause of change in the number of birds in their region, in addition to possible changes in total population size and/or changes in habitat suitability. As importantly, new wintering and staging areas may be unprotected, whereas historical wintering and staging areas may become devoid of birds as distributions retract northwards. This creates a major and novel set of challenge for the effective safeguard of populations, and necessitates a new, more flexible, protection strategy. Such flexible site safeguard programmes need to be underpinned by sound monitoring protocols to inform upon, and deal with, shifting distributions of animals (Pressey et al., 2007; Hodgson et al., 2009), including waterbirds. However, even static networks of protection areas may support climate driven range shifts (Thomas et al., 2012), but there is an urgent need to evaluate the importance of the existing networks of conservation areas, now and in the future.

Many waterbird species are highly prized game species and millions are harvested annually throughout Europe (Hirschfeld \& Heyd, 2005). Redistribution of waterbird species may affect population management in at least two different ways. Firstly, populations shifting toward the north will exhibit an apparent negative population trend in the south and a corollary, apparent positive population trend in the north (as shown by this study). Thus, shifts in the distributions of populations may induce bias in monitoring schemes, and, if not taken into account, may lead to management decisions being made on the basis of false information. This effect may be of special importance in the north, where large, apparent population increases may lead to relaxed harvesting restrictions, despite populations not actually increasing (or even decreasing), but merely being redistributed in winter during the hunting season. Secondly, the redistribution of one species of waterbird may have repercussions on the hunting pressure of others. For example, if an abundant quarry species becomes locally rare due to climate driven redistribution, this could shift harvesting pressure to alternative species. On the other hand, a locally rare species may become abundant as a result of climate change, increasing the hunting pressure on that particular species. Such harvesting pressure interactions between species have not yet been recorded in hunting, but they have been suggested to occur in fisheries (Cheung et al., 2012). Thus, both local and international wildlife management schemes will need to unite their efforts to monitor the flyway-wide population sizes of waterbird, as well as the speciesspecific bag sizes, to avoid overexploitation of locally common species.

Species-specific range shifts may lead to altered interactions both between and within species, either through competition or through changed predator-prey interactions (Bretagnolle \& Gillis, 2010). The changes in abundance we have documented in this study are likely to affect inter- and intra-specific competition, as all three species are now exploiting winter food resources that were formerly denied them by ice, and hence inaccessible before spring. Several duck species show sexual segregation in wintering areas (e.g., Carbone \& Owen, 1995), which may lead the sexes to exhibit differential responses to climate change. Such sex-specific effects of climate change may lead to alterations in global sex ratios through differential exposure to mortality (Lehikoinen et al., 2008). The densities of natural predators increase towards the south (Guillemain et al., 2007), wherefore the sex migrating further south may experience increased 
predation mortality. This gradient in predation pressure may, together with the energetic costs of migration, be a fundamental reason why waterbirds winter as far northeast as climatic conditions allow. We encourage further studies to examine how the effects of waterbird distribution shifts may ripple through wetland ecosystems, affecting, for example, waterbird species interactions, different predator guilds and hunting bag sizes. Such monitoring efforts need to be deployed at both the national and the flyway levels to accurately assess the potential population consequences that may occur as a result of range shifts.

We conclude that the three European duck species examined here have shown rapid northeastward shifts in their wintering distributions, and an exponential increase in abundance at the northeastern edge of their flyways, as a direct response to increased temperatures. These findings show that climate-driven changes in animal distributions may be rapid, are currently on-going and there is urgent conservation and management actions, as well as further research into the effects of climate change on animal distributions.

\section{Acknowledgements}

We acknowledge the selfless contribution of many thousands of volunteers who have collected and submitted waterbird count data upon which we based our analyses. We also thank all coordinators of the national monitoring programmes to whom data have been submitted. Antti Halkka helped with accessing the Climate Explorer. This project was supported by the NordForsk Top Research Initiative Nordic Waterbirds and Climate Network (NOWAC). The Dutch waterbird census scheme is part of a governmental ecological surveillance ('NEM'), carried out in association with Statistics Netherlands and supported by Dutch Ministry of Economic Affairs and the Ministry of Infrastructure and the Environment. The UK's Wetland Bird Survey is a partnership of the British Trust for Ornithology, Royal Society for Protection of Birds and Joint Nature Conservation Committee, in association with Wildfowl and Wetlands Trust. The Swiss waterbird census is supported by the Federal Office for the Environment. In Germany, the waterbird census is supported by the Federal Nature Conservation Agency (BfN) and federal state agencies within the national bird monitoring framework. In Finland, Ministry of Environment has funded winter bird censuses in Aland Islands. The Irish Wetland Bird Survey is a joint programme of BirdWatch Ireland and the National Park and Wildlife Service. I. T. was funded by the Northern Ireland Environment Agency, Quercus, Queen's University Belfast and an Aarhus University AGSoS PhD School Visiting Grant. A. D. F. was part funded by the Danish Nature Agency. K. J. was funded by The Finnish Cultural Foundation and The Academy of Finland (grant no. 128039).

\section{References}

Austin GE, Rehfisch MM (2005) Shifting nonbreeding distributions of migratory fauna in relation to climate change. Global Change Biology, 11, 31-38.
Bretagnolle V, Gillis H (2010) Predator-prey interactions and climate change. In: Effects of Climate Change on Birds (eds Møller AP, Fiedler W, Berthold P), pp. 227248. Oxford University Press, New York.

Brommer J, Møller AP (2010) Range margin changes, life history and ecology. In: Effects of Climate Change on Birds (eds Møller AP, Fiedler W, Berthold P), pp. 249 274. Oxford University Press, New York.

Burnham K, Anderson D (2002) Model Selection and Multimodel Inference: A Practical Information-Theoretic Approach (2nd edn). Springer-Verlag, New York, USA.

Carbone C, Owen M (1995) Differential migration of the sexes of the Pochard Aythya ferina: results from a European survey. Wildfowl, 46, 99-108.

Chen IC, Hill JK, Ohlemüller R et al. (2011) Rapid range shifts of species associated with high level of climate warming. Science, 333, 1024-1026.

Cheung WLL, Pinnegar J, Merino G et al. (2012) Review of climate change impacts on marine fisheries in the UK and Ireland. Aquatic Conservation: Marine and Freshwater Ecosysems, 22, 368-388.

Cramp S, Simmons KEL (1977) The Birds of the Western Palearctic, vol. 1. Oxford University Press, Oxford.

Crowe O, Austin GE, Colhoun $\mathrm{K}$ et al. (2008) Estimates and trends of waterbird numbers wintering in Ireland, 1994/95 to 2003/04. Bird Study, 55, 66-77.

Dalby L, Fox AD, Petersen IK et al. (2013) Temperature does not dictate the wintering distributions of European dabbling duck species. Ibis, 155, 80-85.

Deceuninck B, Maillet N, Ward A et al. (2012) Synthèse des dénombrements d'anatidés et de foulques hivernant en France à la mi-janvier 2011. Rapport WI/LPO/MEDDTLDEB.

Delany S (2005) Guidelines for Participants in the International Waterbird Census (IWC). Wetlands International, Wageningen, The Netherlands.

Gourlay-Larour ML, Schricke V, Sorin C et al. (2012) Movement of wintering diving ducks: new insights from nasal saddled individuals. Bird Study, 59, 266-278

Guillemain M, Arzel C, Legagneux P et al. (2007) Predation risk constrains the plasticity of foraging behaviour in teals, Anas crecca: a flyway-level circumannual approach. Animal Behaviour, 73, 845-854.

Guillemain M, Fuster J, Lepley M et al. (2009) Winter site fidelity is higher than expected for Eurasian Teal Anas crecca in the Camargue, France. Bird Study, 56, 272-275.

Hildén O, Koskimies P, Väisänen RA (1991) Winter bird census. In: Monitoring Bird Populations (eds Koskimies P, Väisänen RA), pp. 19-26. Zoological Museum, Finnish Museum of Natural History, Helsinki, Finland.

Hirschfeld A, Heyd A (2005) Mortality of migratory birds caused by hunting in Europe: bag statistics and proposals for the conservation of birds and animal welfare. Berichte zum Vogelschutz, 42, 47-73.

Hodgson JA, Thomas CD, Wintle BA et al. (2009) Climate change, connectivity and conservation decision making: back to basics. Journal of Applied Ecology, 46, 964 969.

Hofer J, Korner-Nievergelt F, Korner-Nievergelt P et al. (2005) Herkunft und Zugverhalten von in der Schweiz überwinternden Reiherenten Aythya fuligula: eine Ringfundanalyse. Der Ornithologische Beobachter, 102, 181-204.

Hornman M, van Roomen M, Hustings FH, Koffijberg K, van Winden E, Soldaat L (2013). Populatietrends van overwinterende en doortrekkende watervogels in Nederland in 1975-2010 [Population trends in wintering and migrating waterbirds in The Netherlands in 1975-2010]. Limosa 85, 97-116.

Intergovernmental Panel on Climate Change (IPCC) (2007) Climate Change 2007: Synthesis Report. Fourth Assessment Report. IPCC, Geneva, Switzerland.

Jiguet F, Devictor V, Ottvall R et al. (2010) Bird population trends are linearly affected by climate change along species thermal ranges. Proceedings of the Royal Society, Series B, 277, 3601-3608.

Keller V (2011) Die Schweiz als Winterquartier für Wasservögel. Avifauna Report Sempach 6. Schweizerische Vogelwarte, Sempach.

Koskimies P (1993) Population sizes and recent trends of breeding and wintering birds in Finland. Linnut, 28, 6-15.

Kujala H, Araújo MB, Thuiller W et al. (2011) Misleading results from conventional gap analysis - messages from warming north. Biological Conservation, 144, 2450-2458.

La Sorte FA, Thompson FR (2007) Poleward shifts in winter ranges of North American birds. Ecology, 88, 1803-1812.

Lehikoinen A, Jaatinen K (2012) Delayed autumn migration in Northern European waterfowl. Journal of Ornithology, 153, 563-570.

Lehikoinen A, Kilpi M, Öst M (2006) Winter climate affects subsequent breeding success of common eiders. Global Change Biology, 12, 1355-1365.

Lehikoinen A, Christensen TK, Öst M et al. (2008) Large-scale change in the sex ratio of a declining eider population. Wildlife Biology, 14, 288-301.

Ma Z, Cai Y, Li B, Chen J (2010) Managing wetland habitats for waterbirds: an international perspective. Wetlands, 30, 15-27. 
Maclean IMD, Austin GE, Rehfisch MM et al. (2008) Climate change causes rapid changes in the distribution and site abundance of birds in winter. Global Change Biology, 14, 2489-2500.

Musgrove AJ, Austin GE, Hearn RD, Holt CA, Stroud DA, Wotton SR (2011) Overwinter population estimates of British waterbirds. British Birds, 104, 364-397.

Nilsson L (2008) Changes in numbers and distribution of wintering waterfowl in Sweden during forty years, 1967-2006. Ornis Svecica, 18, 135-226.

Pannekoek J, van Strien A (2004) TRIM 3 Manual (TRends E Indices for Monitoring Data). Research Paper 0102, Statistics Netherlands, Voorburg, the Netherlands.

Parmesan C (2006) Ecological and evolutionary responses to recent climate change. Annual Review of Ecology, Evolution and Systematics, 37, 637-669.

Parmesan C, Ryrholm N, Stefanescu C et al. (1999) Poleward shifts in geographical ranges of butterfly species associated with regional warming. Nature, 399, 579-583.

Perdeck AC, Clason C (1980) Some Results of Waterfowl Ringing in Europe. IWRB Special Publication No. 1. International Waterfowl Research Bureau, Slimbridge, UK

Petersen IK, Nielsen RD, Pihl S et al. (2010) Landsdækkende optælling af vandfugle $i$ Danmark, vinteren 2007/2008. Danmarks Miljøundersøgelser, Aarhus Universitet, Arbejdsrapport fra DMU nr. 261. Available at: http://www.dmu.dk/Pub/AR261. pdf (accessed 31 January 2013).

Petersen MR, Douglas DC, Wilson HM et al. (2012) Effects of sea ice on winter site fidelity of Pacific Common Eiders (Somateria mollissima v-nigrum). Auk, 129, 399-408.

Pöysä H, Rintala J, Lehikoinen A et al. (2013) The importance of hunting pressure, habitat preference and life history for population trends of breeding waterbirds in Finland. European Journal of Wildlife Research, 59, 245-256. doi: 10.1007/s10344-012-0673-8

Pressey RL, Cabeza M, Watts ME et al. (2007) Conservation planning in a changing world. Trends in Ecology and Evolution, 22, 583-592.

Rainio R, Laaksonen T, Ahola M et al. (2006) Climatic responses in spring migration of boreal and arctic birds in relation to wintering area and taxonomy. Journal of Avian Biology, 37, 507-515.

Rendón MA, Green AJ, Aguilera E et al. (2008) Status, distribution and long-term changes in the waterbird community wintering in Donana, south-west Spain. Biological Conservation, 141, 1371-1388.

Ridgill SC, Fox AD (1990) Cold Weather Movements of Waterfowl in Western Europe. IWRB Special Publication 13, International Waterfowl and Wetlands Research Bureau, Slimbridge, UK.

Rönkä M, Saari CLV, Lehikoinen EA et al. (2005) Environmental changes and population trends of breeding waterfowl in northern Baltic Sea. Annales Zoologici Fennici, 42, 587-602.

Scott DA, Rose PM (1996) Atlas of Anatidae populations in Africa and Western Eurasia. Wetlands International Publication No. 41, Wetlands International, Wageningen, The Netherlands.

Skov H, Heinänen S, Zydelis R, et al. (2011) Waterbird Populations and Pressures in the Baltic Sea. Nordic Council of Ministers, Copenhagen, Denmark.
Thomas CD, Gillingham PK, Bradbury RB, Roy DB et al. (2012) Protected areas facilitate species' range expansions. Proceedings of the National Academy of Sciences of the USA, 109, 14063-14068.

Vähätalo AV, Rainio K, Lehikoinen A, Lehikoinen E (2004) Spring arrival of birds depends on the North Atlantic Oscillation. Journal of Avian Biology, 35, 210-216.

Venäläinen A, Tuomenvirta H, Drebs S (2005) A Basic Finnish Climate Data Set 1961-2000 - Description and Illustrations. Meteorological Publications, Finnish Meteorological Institute, Helsinki.

Ward HW, Dau CD, Tibbitts TL, Sedinger JS et al. (2009) Change in abundance of Pacific Brant wintering in Alaska: evidence of a climate warming effect. Arctic, 62 301-311

Wetlands International (2006) Waterbird Population Estimates (4th edn). Wetlands International, Wageningen, The Netherlands.

Wetlands International (2012) Waterbird Population Estimates. Available at: wpe.wetlands.org (accessed 30 October 2012).

Williams M (1993) Wetlands: A Threatened Landscape. Blackball Publishers, Oxford.

\section{Supporting Information}

Additional Supporting Information may be found in the online version of this article:

Figure S1. Early winter temperature in North Europe. (a) The spatial correlation of December temperature in southern Finland (defined within the black line on the map) during years 1979-2009 based on Climate Explorer of the Royal Netherlands Meteorological Institute (http://climexp.knmi. $\mathrm{nl}$ ). (b) The mean early winter (16 November to 15 January) temperature in southern Finland (defined in map b; mean of daily means of all $10 \times 10 \mathrm{~km}$ grids in the study area) during winters 1979/1980-2009/2010. The line represents the increasing trend in temperature (beta $=+0.12 \pm 0.06^{\circ} \mathrm{C}$, $F=4.85, \mathrm{df}=29, P=0.035$ ).

Table S1. AICc differences in two different models (Model 1 = direct effect of temperature, Model $2=$ temperature difference between two subsequent years) in each country in tufted duck, goldeneye and goosander. Models where $\triangle \mathrm{AICc}$ was larger than 2 are in bold 